\title{
Manual versus automatic bladder wall thickness measurements: a method comparison study
}

\author{
Matthias Oelke $\cdot$ Charalampos Mamoulakis • \\ Dirk T. Ubbink · Jean J. de la Rosette $\cdot$ Hessel Wijkstra
}

Received: 18 November 2008 / Accepted: 4 February 2009 / Published online: 24 February 2009

(C) The Author(s) 2009. This article is published with open access at Springerlink.com

\begin{abstract}
Purpose To compare repeatability and agreement of conventional ultrasound bladder wall thickness (BWT) measurements with automatically obtained BWT measurements by the BVM 6500 device.

Methods Adult patients with lower urinary tract symptoms, urinary incontinence, or postvoid residual urine were urodynamically assessed. During two subsequent cystometry sessions the infusion pump was temporarily stopped at 150 and $250 \mathrm{ml}$ bladder filling to measure BWT with conventional ultrasound and the BVM 6500 device. For each method and each bladder filling, repeatability and variation was assessed by the method of Bland and Altman.

Results Fifty unselected patients (30 men, 20 women) aged 21-86 years (median 62.5 years) were prospectively evaluated. Invalid BWT measurements were encountered in $2.1-14 \%$ of patients when using the BVM 6500 versus $0 \%$ with conventional ultrasound (significant only during the
\end{abstract}

M. Oelke and C. Mamoulakis have equally contributed to the manuscript.

\section{Oelke $(\bowtie)$}

Department of Urology and Urologic Oncology,

Hannover Medical School, Carl-Neuberg-Str. 1,

30625 Hannover, Germany

e-mail: oelke.matthias@mh-hannover.de

M. Oelke · C. Mamoulakis · J. J. de la Rosette $\cdot$ H. Wijkstra Department of Urology, Academic Medical Center,

Amsterdam, The Netherlands

\section{T. Ubbink}

Department of Quality Assurance and Process Innovation and Surgery, Academic Medical Center,

Amsterdam, The Netherlands second measurement at $150 \mathrm{ml}$ bladder filling). Mean difference in BWT values between the measurements of one technique was -0.1 to $+0.01 \mathrm{~mm}$. Measurement variation between replicate measurements was smaller for conventional ultrasound and the smallest for $250 \mathrm{ml}$ bladder filling. Mean difference between the two techniques was $0.11-0.23 \mathrm{~mm}$ and did not differ significantly. The BVM 6500 device was not able to correctly measure BWTs above $4 \mathrm{~mm}$.

Conclusions Both BWT measurements are repeatable and agree with each other. However, conventional ultrasound measurements have a smaller measurement variance, can measure BWT in all patients, and BWTs above $4 \mathrm{~mm}$.

Keywords Bladder wall thickness · Ultrasound · BVM $6500 \cdot$ Repeatability $\cdot$ Accuracy
Abbreviations
BWT Bladder wall thickness
BS Bladder scan, automatic BWT measurement with the BVM 6500 device, Verathon ${ }^{\circledR}$
$\mathrm{BS}_{150 \mathrm{~A}}$ BS during first urodynamic investigation at $150 \mathrm{ml}$ bladder filling
$\mathrm{BS}_{250 \mathrm{~A}}$ BS during first urodynamic investigation at $250 \mathrm{ml}$ bladder filling
$\mathrm{BS}_{150 \mathrm{~B}} \mathrm{BS}$ during second urodynamic investigation at $150 \mathrm{ml}$ bladder filling
$\mathrm{BS}_{250 \mathrm{~B}} \mathrm{BS}$ during second urodynamic investigation at $250 \mathrm{ml}$ bladder filling
US Ultrasound, BWT measurement with conventional ultrasound machine
$\mathrm{US}_{150 \mathrm{~A}}$ US during first urodynamic investigation at $150 \mathrm{ml}$ bladder filling
$\mathrm{US}_{250 \mathrm{~A}}$ US during first urodynamic investigation at 
$\mathrm{US}_{150 \mathrm{~B}}$ US during second urodynamic investigation at $150 \mathrm{ml}$ bladder filling

$\mathrm{US}_{250 \mathrm{~B}}$ US during second urodynamic investigation at $250 \mathrm{ml}$ bladder filling

SD Standard deviation

95\% CI $95 \%$ confidence interval

\section{Introduction}

Ultrasound bladder wall thickness (BWT) measurements became popular for measuring, quantifying, and monitoring bladder outlet obstruction in men [1-5], for detecting detrusor overactivity in women [6-8], and for assessing urethral valves or abnormal urethral function in children [9, 10] which are all associated with increased BWT. Ultrasound BWT measurements offer the advantage of detecting noninvasively the bladder wall response to lower urinary dysfunction; thus, avoiding expensive, potentially harmful, time- and material-consuming urodynamic investigations in these particular patient groups. Longitudinal studies on bladder outlet obstruction or other forms of bladder dysfunction are still missing because patients were not willing to accept repeated urodynamic measurements. Ultrasound BWT measurements might therefore be used for epidemiological or clinical studies, in which large number of healthy volunteers or patients can be repeatedly screened and classified without being submitted to invasive urodynamic investigations.

Experienced centers have demonstrated small intra- and inter-observer variabilities of conventional ultrasound BWT measurements in the range of $\leq 5$ and $4-12 \%$, respectively $[1,4]$. However, this experience originates from single centers and remains limited to a small group of investigators. This, together with the fact that the learning curve is not negligible, might hinder new investigators in employing this technique and limit its widespread use [11]. Therefore, a machine for automatic measurements of BWT is desirable. Such a machine was introduced by Verathon ${ }^{\circledR}$ (formerly Diagnostic Ultrasound ${ }^{\circledR}$; Bothell, WA, USA). BVM 6500 device is a small, light, battery-powered, portable ultrasound machine that aims to measure BWT and bladder volume automatically and accurately at bladder filling volumes between 100 and $400 \mathrm{ml} \mathrm{[12].} \mathrm{The}$ 3.7 MHz scanner of BVM 6500 has to be positioned suprapubically on the skin of the lower abdomen exactly on the position where the conventional ultrasound array would usually be located for BWT measurements. Via an internet connection, the scanned image data has to be transmitted to a server computer in the USA, where the bladder is delineated and BWT is measured. The scanned images and results are returned to the sender after approximately $2 \mathrm{~min}$.
No study has ever dealt with the repeatability and agreement of BWT measurements by either technique which, however, needs to be confirmed before conducting trials on the clinical usefulness of BWT measurements. We therefore initiated this study to investigate whether (1) manually and automatically obtained BWT measurements are repeatable, (2) repeatability depends on bladder filling volume, and (3) automatically obtained values are comparable with hand-measured values of an experienced investigator using conventional ultrasound machines.

\section{Materials and methods}

Patients and study design

Adult male and female patients with an indication for urodynamic investigation in terms of their workup for lower urinary tract symptoms, urinary incontinence, or postvoid residual urine were asked to participate in this prospective study between April and October 2007. The trial was conducted according to the regulations of the local ethics committee. All patients were fully informed about the study protocol and gave their consent before the measurements.

\section{Examination protocol}

Each patient was placed in the lithotomy position and the bladder was emptied with a $12 \mathrm{~F}$ lubricated transurethral catheter by the investigator. A $6 \mathrm{~F}$ transurethral, doublelumen catheter was inserted into the bladder and a $10 \mathrm{~F}$ single-lumen catheter into the rectum. The empty bladder was confirmed by a suprapubically positioned dynamic 9-4 MHz ultrasound array (iU22; Philips ${ }^{\circledR}$, Eindhoven, The Netherlands). Afterwards, all patients were transferred to a more convenient sitting position. The bladder was filled with sterile saline solution of $37^{\circ} \mathrm{C}$ at a bladder filling rate of $25-30 \mathrm{ml} / \mathrm{min}$. Urodynamic investigations (Ellipse, Andromeda, Taufkirchen, Germany) were performed according to the "good urodynamic practice" standards recommended by the International Continence Society [13].

At $150 \mathrm{ml}$ of bladder filling the infusion pump was temporarily stopped to measure anterior BWT, first with the bladder scan (BS) BVM $6500\left(\mathrm{BS}_{150 \mathrm{~A}}\right)$ and immediately afterwards with the conventional dynamic $9-4 \mathrm{MHz}$ ultrasound (US) scanner $\left(\mathrm{US}_{150 \mathrm{~A}}\right)$, as previously described $[3,11,14]$. The average value of three US measurements at the anterior bladder wall was used for further calculation. BS data were sent to the Verathon ${ }^{\circledR}$ central server via a specific internet homepage using a personal login code. In the meantime, the bladder was filled until $250 \mathrm{ml}$ and BWT measurements were repeated $\left(\mathrm{BS}_{250 \mathrm{~A}}\right.$ and $\left.\mathrm{US}_{250 \mathrm{~A}}\right)$. Afterwards, the bladder was filled until the patient reported a 
strong desire to void and a pressure-flow study followed. After the voiding phase, postvoid residual urine volume was measured via the transurethral catheter and the bladder was once more checked for emptiness with the conventional ultrasound array.

The urodynamic investigation was repeated immediately afterwards exactly as described above and ultrasound BWT measurements were performed during the second cystometry at 150 and $250 \mathrm{ml}$ again $\mathrm{BS}_{150 \mathrm{~B}}$ and $\mathrm{US}_{150 \mathrm{~B}} ; \mathrm{BS}_{250 \mathrm{~B}}$ and US ${ }_{250 \mathrm{~B}}$ ). All measurements were performed by a single experienced urologist (M.O.).

\section{Statistical evaluation}

Repeatability of each BWT measurement method from replicated measurements at both bladder filling volumes separately was assessed with the methodology described by Bland and Altman [15]. For each method and at each specific bladder filling volume, the distribution of differences between replicate measurements was plotted against their average. The existence of any systematic difference between replicates, their variation (indicated by mean $\pm 2 \mathrm{SD}$ ), and any possible trend of the distribution of differences across the range of BWT measurements was assessed graphically. Only patients with two valid measurements were included in the analysis. In order to compare the two different methods of BWT measurement at each bladder filling volume separately, and to determine the agreement between them, the same methodology was applied based on valid measurements by both modalities during the first urodynamic investigation only. The onesample $t$ test was applied to test whether mean differences between replicates differed from zero. McNemar's test was used to compare the proportions of patients with valid measurements by the same modality at different bladder filling volumes and the proportions of patients with valid measurements by different modalities at the same bladder filling volume. A probability of 0.05 or less (two-tailed) was considered to indicate statistical significance. The data were analyzed with SPSS (version 15.0; Chicago, IL, USA).

\section{Results}

Fifty unselected patients aged 21-86 years (median: 62.5 years; men/women: 30/20) submitted to urodynamic investigation were included in the study. Patient characteristics are summarized in Table 1. All patients reached the bladder filling volume of $150 \mathrm{ml}$ during cystometry but only 47 patients reached $250 \mathrm{ml}$.

Valid BWT measurements with US could be performed during both urodynamic investigations in all 50 patients at $150 \mathrm{ml}$ and all 47 patients at $250 \mathrm{ml}$. In contrast, BS failed to deliver a valid measurement after central server evaluation in four patients (8\%) during the first and seven patients (14\%) during the second measurement at $150 \mathrm{ml}$. The same happened at $250 \mathrm{ml}$ in one (2.1\%) and three patients (6.4\%) during the first and second cystometry, respectively. The proportion of patients with valid measurements by each modality at $150 \mathrm{ml}$ did not differ significantly in the first urodynamic investigation ( $p=0.125$ ), but was significantly higher for US in the second urodynamic investigation $(p=0.016)$. The proportions did not differ significantly at $250 \mathrm{ml}$ (first/second urodynamic investigation: $p=1.0 /$ 0.25 ). No significant differences in patients with valid measurements were detected between 150 and $250 \mathrm{ml}$ bladder filling volumes for BS in either urodynamic investigation (first/second urodynamic investigation: $p=0.375 / 0.125$ ).

Comparison between ultrasound measurements obtained by the same method

BWT measurement values using US (BS) ranged from 1.1 to $13.5 \mathrm{~mm}(1.8-6.1 \mathrm{~mm})$ at $150 \mathrm{ml}$ and from 1.2 to
Table 1 Characteristics of patients who participated in the prospective study

The patients sought help for lower urinary tract symptoms, urinary incontinence, or postvoid residual urine and were randomly selected regardless of age, body-mass index, or urodynamic diagnosis $P V R$ postvoid residual urine

\begin{tabular}{llll}
\hline & All patients $(n=50)$ & Men $(n=30)$ & Women $(n=20)$ \\
\hline Age (years) & 62.5 & 65.0 & 54.5 \\
Median (range) & $(21-86)$ & $(32-86)$ & $(21-78)$ \\
Body-mass index $\left(\mathrm{kg} / \mathrm{m}^{2}\right)$ & 26.0 & 26.0 & 26.1 \\
Median (range) & $(19.1-40.3)$ & $(19.1-36.1)$ & $(19.5-40.3)$ \\
Primary urodynamic diagnosis & & & \\
Detrusor overactivity \pm incontinence & 10 & 6 & 4 \\
Stress urinary incontinence & 9 & 0 & 9 \\
Increased bladder sensation & 4 & 1 & 3 \\
Bladder outlet obstruction & 17 & 17 & 0 \\
Detrusor underactivity & 8 & 6 & 2 \\
Dysfunctional voiding and PVR & 2 & 0 & 2 \\
\hline
\end{tabular}


$12.6 \mathrm{~mm}(1.5-3.9 \mathrm{~mm})$ at $250 \mathrm{ml}$ bladder filling. There was no statistical difference between mean BWT values when the same ultrasound method was compared during the first or second measurement either at 150 or $250 \mathrm{ml}$. All differences between repeated measurements were distributed evenly around their mean without any evident trend across the respective ranges of BWT measurements (Fig. 1). Mean differences of replicate measurements were subtle $(-0.1$ to $+0.01 \mathrm{~mm}$ ). Both modalities were repeatable at both bladder filling volumes since no systematic differences were observed between replicates. The variation of differences between replicates (mean $\pm 2 \mathrm{SD}$ ) was higher at $250 \mathrm{ml}$
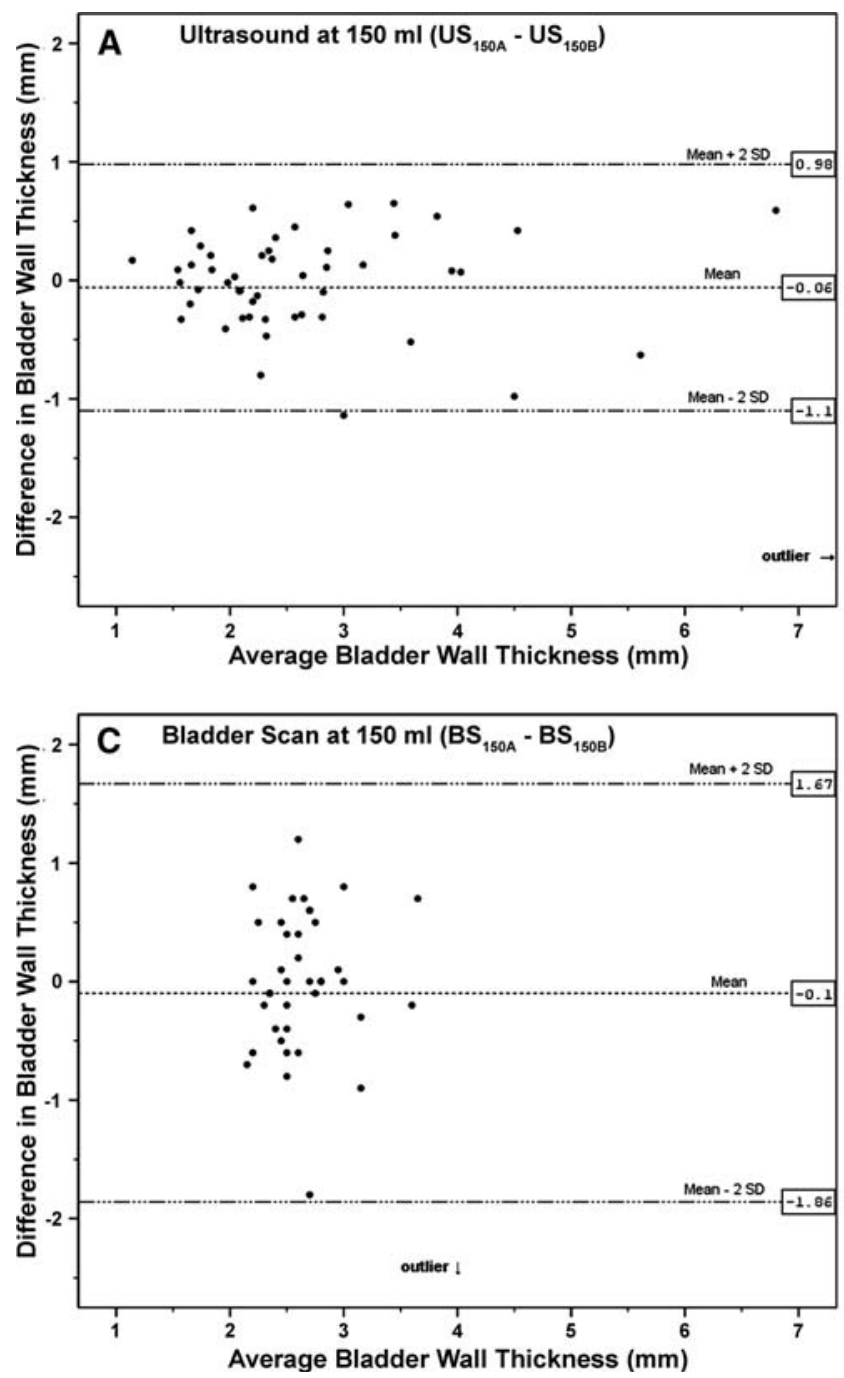

Fig. 1 Repeatability of bladder wall thickness measurements: Ultrasound at $150 \mathrm{ml} ; n=50$ replicates (a) and $250 \mathrm{ml} ; n=47$ replicates (b), bladder scan at $150 \mathrm{ml} ; n=40$ replicates (c) and $250 \mathrm{ml} ; n=43$ replicates $(\mathbf{d})$. The mean difference between replicates and their variation (mean $\pm 2 \mathrm{SD}$ ) are indicated by respective lines. $95 \% \mathrm{CI}$ of the mean (not shown) are $-0.21 \mathrm{~mm}$ to $+0.09 \mathrm{~mm}(\mathbf{a}),-0.18 \mathrm{~mm}$ to $+0.01 \mathrm{~mm}$ (b), $-0.38 \mathrm{~mm}$ to $+0.18 \mathrm{~mm}$ (c) and $-0.15 \mathrm{~mm}$ to $+0.17 \mathrm{~mm}(\mathbf{d})$. The presence of one outlier is indicated in $\mathbf{a}$ (patient 17), b (patient 17) and $\mathbf{c}$ (patient 16). The exact position of each outlier bladder filling with both modalities. However, the variation was generally higher with BS at both bladder filling volumes compared to the corresponding variation with US.

Comparison between ultrasound measurements obtained by different methods

Comparison of US with BS measurements showed that the mean difference (US - BS) was $0.23 \mathrm{~mm}$ at $150 \mathrm{ml}$ and $0.11 \mathrm{~mm}$ at $250 \mathrm{ml}$ bladder filling (Fig. 2). Mean differences did not differ significantly from zero ( $p=0.362,0.662$ for bladder filling volumes of 150 and
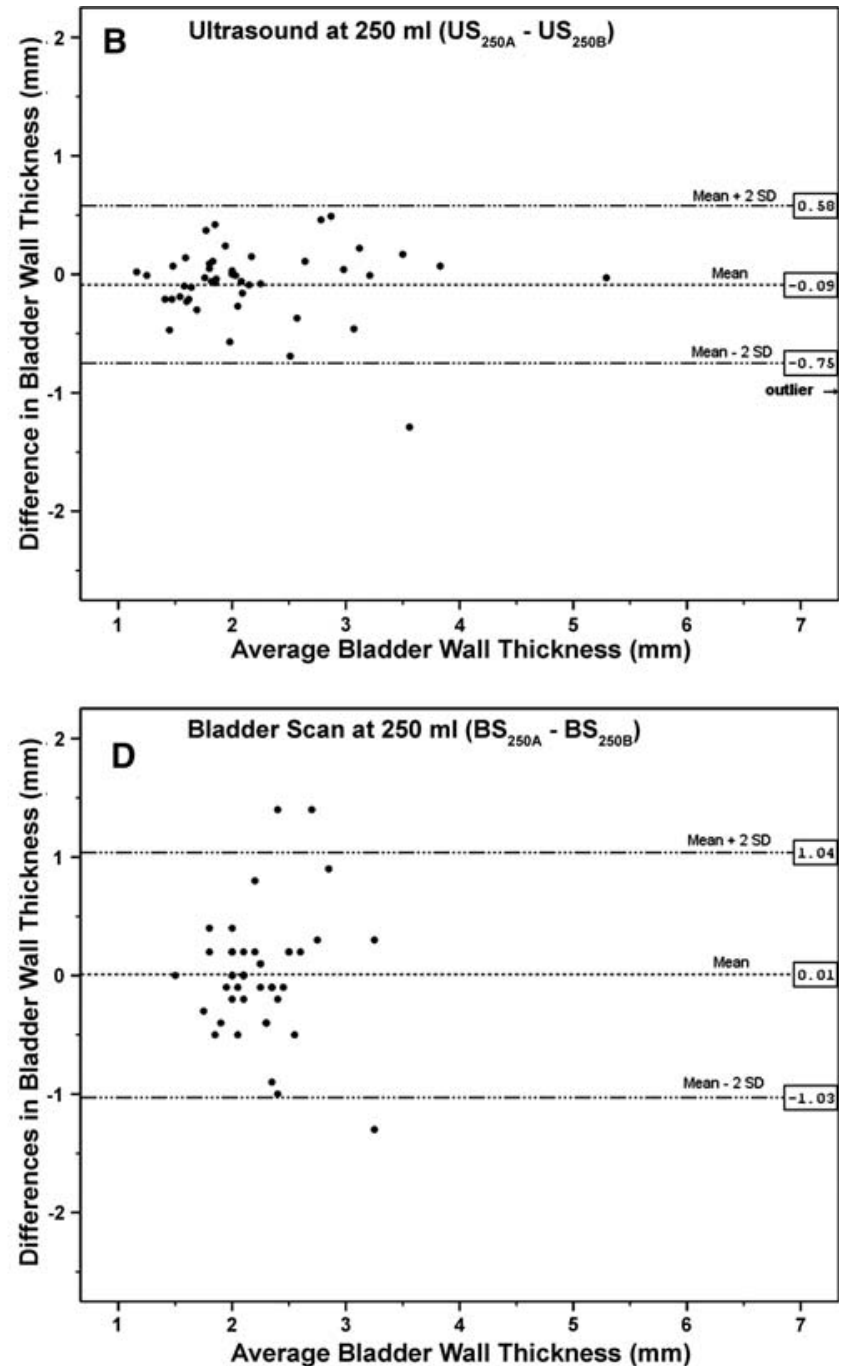

in relation to $x, y$ axes (not shown) is $(12.37,-2.33 \mathrm{~mm})$ in $\mathbf{a},(12.08$, $-0.97 \mathrm{~mm})$ in $\mathbf{b}$ and $(4 \mathrm{~mm},-4.20 \mathrm{~mm})$ in c. There is no obvious trend of the distribution of differences across the range of BWT measurements. Both modalities are repeatable at both bladder filling volumes since no systematic differences are observed between replicates; mean differences do not differ significantly from zero $(p>0.05)$. However, repeatability is improved at the bladder filling volume of $250 \mathrm{ml}$ for both modalities (reduced variation) 


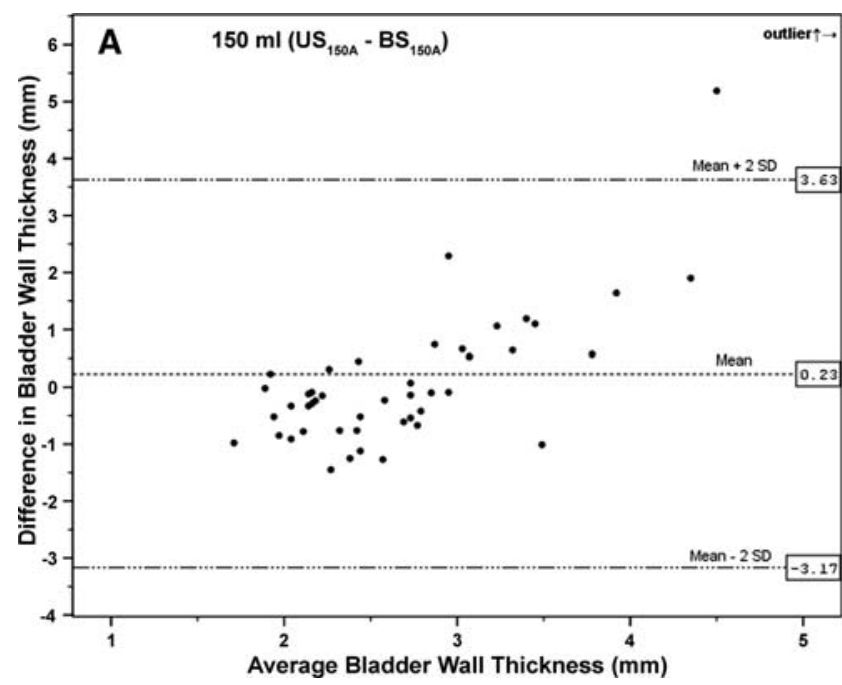

Fig. 2 Comparison of bladder wall thickness measurements with conventional ultrasound and bladder scan based on first urodynamic investigation measurements at $150 \mathrm{ml}$ (a) and $250 \mathrm{ml}$ (b); $n=46$ pairs of measurements. Mean difference between paired measurements and their variation (mean $\pm 2 \mathrm{SD}$ ) are indicated by respective lines. $95 \% \mathrm{CI}$ of the mean (not shown) are -0.27 to $+0.74 \mathrm{~mm}(\mathbf{a}),-0.39$ to $+0.61 \mathrm{~mm}(\mathbf{b})$. The presence of one outlier is indicated in $\mathbf{a}$ and b (patient 17). The exact position of the outlier in relation to $x-y$ axes

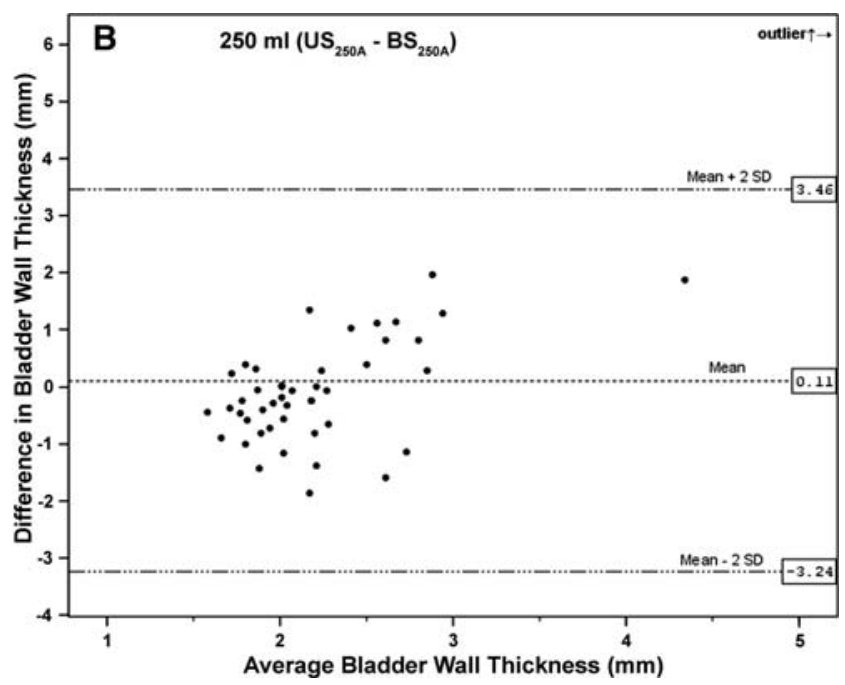

(not shown) is $(6.90,+8.60 \mathrm{~mm})$ in $\mathbf{a}$ and $(6.80,+9.60 \mathrm{~mm})$ in $\mathbf{b}$. There is an obvious positive trend of the distribution of differences across the range of BWT measurements (differences increase for higher BWT values). There is evidence of agreement between the two modalities at both bladder filling volumes since no systematic differences are observed between paired measurements; mean differences do not differ significantly from zero $(p>0.05)$

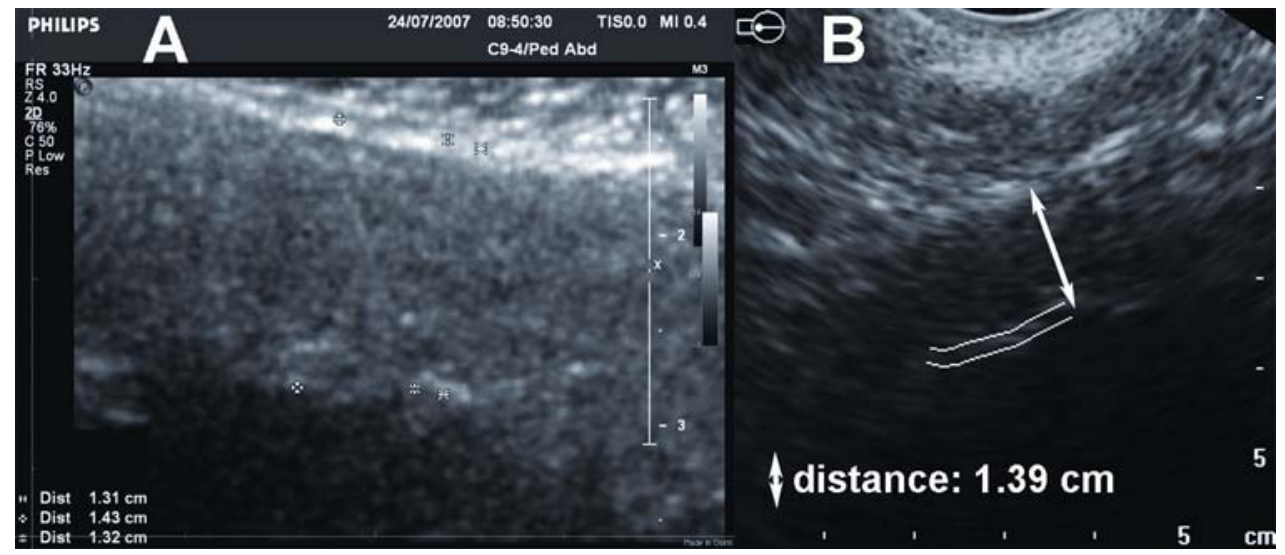

Fig. 3 Bladder wall thickness measurements of a patient with conventional ultrasound (a) in comparison to the corresponding image of the BVM 6500 device (b). The patient had a thick bladder wall due to urodynamically confirmed severe bladder outlet obstruction (patient 17, first measurement at $250 \mathrm{ml}$ ). Bladder wall thickness measured with conventional ultrasound was greater in comparison to the measurement with the BVM 6500 device which measured only the inner part of the anterior bladder wall (double wavy line). The double arrow head in Fig. $3 \mathrm{~b}$ indicates the true bladder wall thickness which is comparable with the measurement value of conventional ultrasound
$250 \mathrm{ml}$, respectively). However, there was a trend towards a higher difference of BWT at higher BWT values which was as high as 11.7 and $11.0 \mathrm{~mm}$ at 150 and $250 \mathrm{ml}$, respectively (concerning a patient with severe bladder outlet obstruction). Direct comparison of the US images with automatically obtained images in patients with thicker anterior bladder walls showed that the BVM 6500 device did not capture the entire anterior bladder wall and measured the inner part of the anterior bladder wall only (Fig. 3).

\section{Discussion}

The BVM 6500 device has to be positioned on the skin of the lower abdomen and aims to measure bladder volume and anterior BWT. The correct position on the lower abdomen and a measurement of good quality are immediately indicated on the display of the BVM 6500 device. If the device is improperly positioned, arrows on the display indicate the direction towards which the device has to be moved to receive images and measurements of good 
quality. Although these suggestions were followed meticulously in all patients and the BVM 6500 indicated measurements with good quality, invalid measurements were still delivered in $2-14 \%$ of patients after sending the data to the central sever computer. Since we proceeded with the bladder filling during the central computer evaluation time span of approximately $2 \mathrm{~min}$, invalid measurements could not be repeated. An integrated evaluation function inside the BVM 6500 without data transfer could have delivered the measurement results faster and might solve this problem in the future. Invalid measurements appeared in different men and women indicating that gender or tissue properties were not responsible for missing values.

Chalana et al. [12] suggested measuring BWT with the BVM 6500 between 100 and $400 \mathrm{ml}$ of bladder filling. However, BWT should be measured according to the official Verathon ${ }^{\circledR}$ handbook for the BVM 6500 device at a bladder filling volume between 100 and $300 \mathrm{ml}$. We evaluated BWT at a bladder filling of 150 and $250 \mathrm{ml}$ to ensure measuring within the recommended volume range. Automatic BWT measurements at lower or higher volumes than recommended might have provided different results. In contrast to these recommendations, conventional ultrasound BWT measurements are possible at every state of bladder filling [14].

Questions regarding the comparability of bladder filling volumes between the first and second round of BWT measurements might arise. Since BWT is dependent on bladder filling until $250 \mathrm{ml}[3,14]$, differences in bladder fillings could result in different BWT values. We emptied the bladder completely before starting each urodynamic study, the patients did not drink during the investigations, and the bladders were filled at the same speed during both cystometries. As urine production is believed to be continuous, we assume that the same amount of urine has been added to the infused bladder volume during the first and second urodynamic investigation. Although the assessment of an exact bladder filling volume (e.g. 150 or $250 \mathrm{ml}$ ) might not be absolutely accurate, a difference during the first and second round of BWT measurements is regarded subtle and therefore negligible.

Differences between US and BS measurements could have been attributed to different ultrasound frequencies. We used a dynamic 9-4 MHz ultrasound scanner for US measurements, whereas the BVM 6500 device uses a $3.7 \mathrm{MHz}$ scanner. Because the US scanner was located on the skin of the lower abdomen with a distance to the bladder of only a few centimeters, ultrasound frequencies close to $9 \mathrm{MHz}$ were used to image the anterior bladder wall. The resolution of ultrasound images is frequency dependent. Ultrasound scanners of 7.5 and $3.5 \mathrm{MHz}$ have a resolution in the order of 0.13 and $0.3 \mathrm{~mm}$, respectively [14]. The use of higher ultrasound frequencies in future generations of automatic BWT scanners would improve the resolution and might decrease the difference between repeated BWT measurements.

The variance of BWT measurements at the same patient was lower with US and the lowest at $250 \mathrm{ml}$; therefore, determination of BWT with US at $250 \mathrm{ml}$ appears to be the most precise technique and volume of all tested. However, we investigated measurement variations only at 150 and $250 \mathrm{ml}$ bladder filling; thus, the variance of measurement results might further decrease at bladder fillings above $250 \mathrm{ml}$.

Thicker anterior bladder walls appeared in patients with bladder outlet obstruction due to benign prostatic hyperplasia. This result is in line with previous findings [1-5]. Although mean BWT of all patients in our study did not differ significantly when US was compared with BS, mean BWT of obstructed patients were lower with the BVM 6500 device. There was no patient with bladder outlet obstruction with automatic BWT measurement above $4 \mathrm{~mm}$, whereas five patients with bladder outlet obstruction had a BWT between 4.1 and $13.5 \mathrm{~mm}$ with conventional ultrasound BWT measurement (mean BWT 2.79 vs. $3.42 \mathrm{~mm}$ ). Direct comparison of ultrasound images of both techniques in obstructed patients showed that the BVM 6500 measured only the inner part of the anterior bladder wall without including the outer part. The BVM 6500 device does not correctly measure BWT in the individual patient with bladder outlet obstruction and, therefore, previously published results seem to be doubtful $[16,17]$. If the investigator could manually change the measurement lines of the BVM 6500 images to indicate the true inner and outer border of the anterior bladder wall, these erroneous measurements could be avoided. Our study was designed to investigate repeatability and accuracy of BWT measurements and included only a small amount of patients with benign prostatic hyperplasia. Therefore, the groups of diseased patients were too small to investigate validity, diagnostic accuracy, or clinical usefulness of BWT measurements. A study based exclusively on patients with benign prostatic hyperplasia with or without bladder outlet obstruction should clarify this matter in the future.

\section{Conclusions}

This is the first study on repeatability and agreement of automatic and conventional ultrasound BWT measurements. Our study of 50 unselected patients with different types of bladder dysfunction provided evidence of good repeatability for both modalities and agreement between them at both bladder filling volumes tested (150 and $250 \mathrm{ml}$ ). Repeatability was shown to be improved at higher bladder filling volumes for both modalities. However, the 
BVM 6500 device could not deliver a valid measurement in up to $14 \%$ of patients, thicker anterior bladder walls could not be measured correctly, and the variation of repeated measurements was higher than with conventional ultrasound. Even though the performance of BVM 6500 device is encouraging, automatic BWT measurements cannot replace hand measurements with conventional ultrasound at this point of development.

Acknowledgments C.M. thanks the Alexander S. Onassis Public Benefit Foundation for a grant offered to attend a clinical fellowship program. The enthusiastic collection of the measurement data and ultrasound images by Ms. Joyce Baard is gratefully acknowledged.

Conflict of interest statement The authors declare that they have no conflict of interest.

Open Access This article is distributed under the terms of the Creative Commons Attribution Noncommercial License which permits any noncommercial use, distribution, and reproduction in any medium, provided the original author(s) and source are credited.

\section{References}

1. Manieri C, Carter SS, Romano G et al (1998) The diagnosis of bladder outlet obstruction in men by ultrasound measurement of bladder wall thickness. J Urol 159:761-765. doi:10.1016/S00225347(01)63723-6

2. Hakenberg OW, Linne C, Mansek A, Wirth MP (2000) Bladder wall thickness in normal adults and men with lower urinary tract symptoms and benign prostatic enlargement. Neurourol Urodyn 19:585-593. doi:10.1002/1520-6777(2000)19:5<585::AID-NA $\mathrm{U} 5>3.0 . \mathrm{CO} ; 2-\mathrm{U}$

3. Oelke M, Höfner K, Wiese B et al (2002) Increase in detrusor wall thickness indicates bladder outlet obstruction (BOO) in men. World J Urol 19:443-452

4. Kessler TM, Gerber R, Burckhard FC et al (2006) Ultrasound assessment of detrusor thickness in men-can it predict bladder outlet obstruction and replace pressure flow study? J Urol 175:2170-2173. doi:10.1016/S0022-5347(06)00316-8

5. Oelke M, Höfner K, Jonas U et al (2007) Diagnostic accuracy of noninvasive tests to evaluate bladder outlet obstruction in men: detrusor wall thickness, uroflowmetry, postvoid residual urine, and prostate volume. Eur Urol 52:827-834. doi:10.1016/j.eururo.2006.12.023

6. Khullar V, Salvatore S, Cardozo L et al (1994) A novel technique for measuring bladder wall thickness in women using transvaginal ultrasound. Ultrasound Obstet Gynecol 4:220-223. doi:10.1046/ j.1469-0705.1994.04030220.x

7. Khullar V, Cardozo LD, Salvatore S, Hill S (1996) Ultrasound: a noninvasive screening test for detrusor instability. Br J Obstet Gynaecol 103:904-908

8. Robinson D, Anders K, Cardozo L et al (2002) Can ultrasound replace ambulatory urodynamics when investigating women with irritative urinary symptoms? BJOG 109:145-148. doi:10.1111/ j.1471-0528.2002.01021.x

9. Cvitkovic-Kuzmic A, Brkljacic B, Ivankovic D, Grga A (2002) Ultrasound assessment of detrusor muscle thickness in children with non-neurogenic bladder/sphincter dysfunction. Eur Urol 41:214-219. doi:10.1016/S0302-2838(01)00023-9

10. Kaefer M, Barnewolt C, Retik AB, Peters CA (1997) The sonographic diagnosis of infravesical obstruction in children: evaluation of bladder wall thickness indexed to bladder filling. J Urol 157:989-991. doi:10.1016/S0022-5347(01)65127-9

11. Oelke M, Wijkstra H (2006) Ultrasound detrusor wall thickness measurements to diagnose bladder outlet obstruction in men. Urodinamica $16: 343-352$

12. Chalana V, Dudycha S, Yuk JT, McMorrow G (2005) Automatic measurement of ultrasound-estimated bladder weight (UEBW) from three-dimensional ultrasound. Rev Urol 7(Suppl 6):S22-S28

13. Schäfer W, Abrams P, Liao L et al (2002) Good urodynamic practices: uroflowmetry, filling cystometry, and pressure-flow studies. Neurourol Urodyn 21:261-274. doi:10.1002/nau.10066

14. Oelke M, Höfner K, Jonas U et al (2006) Ultrasound measurement of detrusor wall thickness in healthy adults. Neurourol Urodyn 25:308-317. doi:10.1002/nau.20242

15. Bland JM, Altman DG (1986) Statistical methods for assessing agreement between two methods of clinical measurement. Lancet $1: 307-310$

16. Al-Housami F, Abrams P (2008) The use of ultrasound-estimated bladder weight in diagnosing bladder outlet obstruction and detrusor overactivity in men. Eur Urol 7(Suppl):131. doi:10.1016/ S1569-9056(08)60241-9 (abstract)

17. Lee K, Lee Y, Lee SE et al (2008) The diagnostic efficacy of three dimensional ultrasound estimated bladder weight corrected by body surface area as an alternative non-urodynamic parameter of bladder outlet obstruction. Neurourol Urodyn 27(Suppl):652-653 (abstract) 